adherence to treatment recommendation (ATR) and recidivism before the 15th day after the day of consultation (need of further consultation due to the same medical problem). Registries included those generated along the first 12 months after the end of the courses.

Results: The TT group generated 175 registries while PBL generated 219. Both groups were formed by 20 non rheumatology second year residents. Proportion of AITR were 73.3 and $60.2 \%$ for BLT and TT groups, respectively $(P<0.001)$. Considering only the registries generated in the first trimester after the courses, those proportions were respectively 80.2 and $79.5 \%$. Proportion of ATR were 69.9 and $55.7 \%$, respectively $(P<0.001)$, however when considering only registries generated in the first trimester those proportions were 77.1 and $76.9 \%$, respectively. Global recidivism rate (number of patients who need a further consultation due to the same medical problem or due to the side effects of their treatment among all patients attended) at the first 15th day since the first assessment was $8.7 \%$ in the PBL group and $17.5 \%$ in the TT group $(P<0.001)$. At the end of both courses a survey to the students were performed. The satisfaction index -measured by a $0-10$ progressive ordinal scale- were 9.1 SD 1.3 for the PBL model and 8.2 SD 1.4 for the TT model $(P<0.05)$.

Conclusions: The pedagogical PBL teaching method shows a better academic impact in terms of concept retention and appliance into the medical practice along the time. In our opinion and according to our experience, most programs of education on transversal topics of rheumatology should be taught using the PBL method.

Disclosure of Interest: None declared

DOI: 10.1136/annrheumdis-2017-eular.3984

\section{OP0067 DEVELOPMENT AND VALIDATION OF A MODEL TO FACILITATE RECOGNITION OF ARTHRITIS BY GENERAL PRACTITIONERS}

B.T. van Dijk, R.M. ten Brinck, H.W. van Steenbergen, A.H. van der Helm-van Mil. Rheumatology, Leiden University Medical Centre, Leiden, Netherlands

Background: Early initiation of treatment of rheumatoid arthritis is strongly associated with an improved outcome, but requires the early identification of arthritis. Physical examination of joints is crucial to this end, but is difficult for general practitioners (GPs) who have little experience. Another difficulty is that GPs see many persons with musculoskeletal symptoms per year but only few patients with clinical arthritis. To promote early recognition of arthritis, the Early Arthritis Recognition Clinic (EARC) was initiated in Leiden, the Netherlands in 2010. GPs were instructed to refer to this clinic in case of doubt on the presence of arthritis (and not to wait and see, or to perform additional laboratory tests). At this clinic, patients filled out a form with questions on their symptoms and were seen by a rheumatologist in a short visit that comprised a full joint examination. As reported previously, this clinic importantly improved the early identification of arthritis and RA (1), but this approach may not be easily implemented in other centres or regions.

Objectives: To assess if a combination of symptoms and signs that are easy to assess can differentiate patients with and without clinical arthritis at joint examination.

Methods: 1,288 patients in whom GPs doubted on the presence of arthritis visited the EARC between 2010 and 2015. Reported symptoms and signs were studied with the presence of synovitis (joint examination by experienced rheumatologist) as outcome. Multivariable logistic regression was used. A model was derived in 644 patients, and validated in the second set of 644 patients.

Results: $41 \%$ of the patients who visited the EARC had arthritis at examination. Age (per year OR 1.02; 95\% Cl 1.01-1.03), male sex (OR 1.8; 95\% Cl 1.3-2.7), symptom duration (4-12 weeks OR $3.83 ; 95 \% \mathrm{Cl} 2.22-6.60)$, morning stiffness $>60$ min (OR 1.7; 95\% Cl 0.9-2.9), difficulty with making a fist (OR 1.6; $95 \% \mathrm{Cl}$ 0.97-2.5), number of tender joints (1-3 tender joints OR 9.7; $95 \% \mathrm{Cl} 1.1-81.8$ ) and self-reported swollen joints (OR $3.5 ; 95 \% \mathrm{Cl} 1.8-7.0$ ) were associated with the presence of arthritis in multivariable analysis. The AUC was 0.75 (SE 0.02) in the derivation set and 0.71 (SE 0.02) in the validation set. To facilitate application in practice, a simplified model was made. This consisted of 7 variables and the total score ranged between $0-7$. The AUC was 0.73 (SE 0.02). Depending on the cut-off, the PPV of the simplified model ranged between 41 and $74 \%$ and the NPV between 100 and $62 \%$. With a cut-off of 4 , the NPV was $86 \%$, PPV $49 \%$, specificity $35 \%$, and sensitivity $91 \%$.

Conclusions: A set of clinical characteristics that can be easily assessed by GPS had a reasonable discriminative ability for clinical arthritis, and can be applied by GPs in case of doubt on the presence of arthritis. This model requires further validation in general practices, but may lead to a tool that could assist GPs in their decision making regarding referral or ordering additional tests for patients with suspected early arthritis.

References:

[1] van Nies JA, et al. Ann Rheum Dis. 2013;72(8):1295-301.

Disclosure of Interest: None declared

DOI: 10.1136/annrheumdis-2017-eular.2981

\section{OP0068 PRACTICES PARTICIPATING IN THE ACR'S RHEUMATOLOGY INFORMATICS SYSTEM FOR EFFECTIVENESS (RISE) NATIONAL REGISTRY SHOW IMPROVEMENTS IN QUALITY OF CARE}

J. Yazdany ${ }^{1}$, R. Myslinski ${ }^{2}$, T. Johansson ${ }^{2}$, S. Kazi ${ }^{3} \cdot{ }^{1}$ Medicine/Rheumatology, University of California, San Francisco, San Francisco; ${ }^{2}$ American College of Rheumatology, Atlanta; ${ }^{3}$ University of Texas Southwestern, Dallas, United States

Background: The ACR launched the RISE registry in 2014 to facilitate quality improvement on a national scale. The registry passively extracts electronic health record (EHR) data from rheumatology practices, aggregates and analyzes these data centrally, and feeds performance on quality measures back to clinicians using a web-based dashboard.

Objectives: We used data from RISE to 1) examine variation in performance on quality measures across practices, and 2) evaluate trends in measure performance over time.

Methods: RISE's informatics platform continuously collects data from the EHRs of participating practices, allowing centralized aggregation and analysis of quality measures. We analyzed data collected between July 1, 2014-July 1, 2016 on all patients seen by 294 clinicians across 63 practices. Measures in the areas of rheumatoid arthritis, drug safety, preventive care and gout were examined. Performance on quality measures, defined as the percentage of eligible patients receiving recommended care, was examined at the practice level. To examine trends in performance over time, we took the subset of practices that continuously participated in RISE since its inception ( $n=44)$, and developed 1) control charts and 2) logistic regression models, in which the outcome was practice-level performance each month and the predictor was time.

Results: Data from 289,812 patients was examined. Mean (SD) age was 59 (16) years, $75 \%$ were female, $21 \%$ were racial/ethnic minorities, and $37 \%$ had public insurance. Most rheumatologists were in a group practice $(73 \%) ; 25 \%$ were in solo practice and $2 \%$ part of a larger health system. Performance on measures varied significantly across practices (Table). The largest gaps were observed for gout and preventive care. For 4 of 5 measures for which the Medicare program has set national benchmarks, average performance of RISE practices exceeded targets. Of 11 measures, performance improved over time on 5 measures $(p<0.05$ in logistic models; see Figure for example control chart), was at goal on 4 measures, and saw no improvement on 2 measures (BMI screening and urate target).

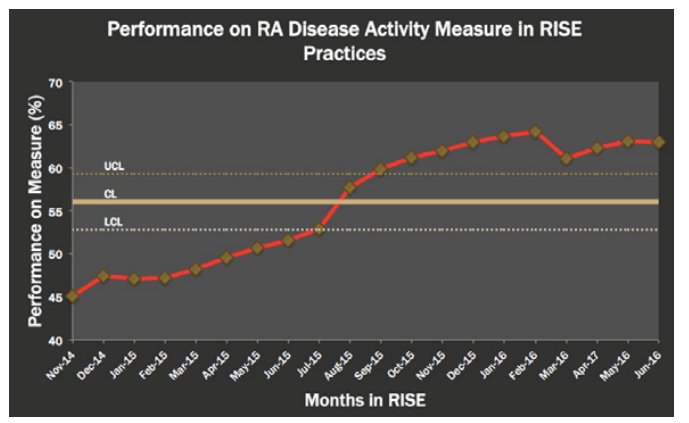

Conclusions: We found significant variation in performance on quality measures across RISE practices, with the largest gaps seen in gout care and preventive care. Some practices have achieved a very high level of performance. Over time, RISE practices demonstrated improvement in over half of the measures

Abstract OP0068 - Table 1

\begin{tabular}{|c|c|c|c|c|c|}
\hline \multirow[t]{2}{*}{ Electronic Quality Measure (eCQM) } & \multirow[t]{2}{*}{$\begin{array}{l}\text { Measure denominator } \\
\text { (N) }\end{array}$} & \multirow[t]{2}{*}{$\begin{array}{l}\text { Average performance across patients } \\
\qquad(\%)\end{array}$} & \multicolumn{2}{|c|}{$\begin{array}{l}\text { Average practice-level performance } \\
\text { (percentile) }\end{array}$} & \multirow[t]{2}{*}{ CMS benchmark } \\
\hline & & & 50th & 100th & \\
\hline RA: Assessment of Disease Activity & 63,472 & 52.1 & 56.1 & 100 & \\
\hline RA: Functional Status Assessment & 63,472 & 50.0 & 56.1 & 100 & \\
\hline RA: DMARD & 63,472 & 90.1 & 91.4 & 98.2 & 9.0 \\
\hline Drug Safety: TB screening pre-biologic & 7,842 & 61.1 & 66.6 & 95.7 & 9.0 \\
\hline Drug Safety: $\geq 1$ High-Risk Medication in Elderly* & 101,820 & 4.7 & 2.8 & 0 & 89.7 \\
\hline Drug Safety: $\geq 2$ High-Risk Medications in Elderly* & 101,820 & 0.1 & 0 & 0 & 57.8 \\
\hline Preventive Care: Tobacco screening and counseling & 219,415 & 85.3 & 89.3 & 99.8 & 68.5 \\
\hline Preventive Care: BMI documentation, follow-up plan & 154,501 & 26.4 & 26.7 & 50.7 & \\
\hline Preventive Care: Blood pressure management & 30,607 & 70.0 & 63.2 & 100 & \\
\hline
\end{tabular}

*Lower number indicates higher performance. 